\title{
Research and Application of Effective Teaching in Japanese Accounting Course
}

\author{
Shanshan Tan ${ }^{1, *}$ \\ ${ }^{1}$ School of Continuing Education, Dalian Jiaotong University, Dalian, Liaoning 116000, China \\ *Corresponding author. Email:tanshan7844828@163.com
}

\begin{abstract}
Japanese accounting refers to the preparation method, entry method and basic accounting system of the enterprise under the premise of Japanese Accounting Standards. The Japanese bookkeeping course is an emerging course in recent years. It has attracted much attention because it can expand the knowledge of Japanese majors and increase employment opportunities. How to design Japanese accounting classrooms and let students actively participate in classroom activities is the key to teaching reform. Based on the O-AMAS teaching model (Objective, Activation, Multi-learning, Assessment, Summary), this paper has carried out a series of research and practical application in the classroom, and discussed its specific reform methods.
\end{abstract}

\section{Keywords: effective teaching, Japanese accounting, O-AMAS teaching model}

\section{INTRODUCTION}

After entering the two keywords of effective teaching and Japanese in China Knowledge Network, a total of 19 papers can be found. The earliest thesis was in 2009, indicating that the research on Japanese teaching in effective teaching started in China around 2009. These 19 theses all focus on the Japanese teaching mode, including analysis of Japanese writing courses (Sangzhuo, 2016), Japanese teaching in higher vocational education (Shang Yongli, 2013), Japanese teaching in secondary vocational education (Liu Zhouxia, 2013), efficient Second Japanese Class (Zhao Dongmeng et al., 2016). The previous research mainly included: Discussion and research application of effective teaching modes of different Japanese courses. Japanese accounting courses, especially accounting courses for Japanese majors, have not been studied and discussed. This article intends to make up for these shortcomings and practice and research on effective teaching models in Japanese accounting courses.

\section{RESEARCH ON JAPANESE ACCOUNTING}

\section{A. Reasons why to set up a Japanese bookkeeping course}

Japanese accounting means the preparation of financial statements, entry methods, and the basic

*Fund: The course "Basic Japanese Bookkeeping" is a first-class undergraduate course at Dalian Jiaotong University in 2019. This thesis is one of the results of course construction. accounting system of an enterprise under the premise of Japanese accounting standards.

Dalian is the gateway to the world in Northeast China. In recent years, with the deepening of the "Belt and Road" strategy, Dalian's location advantage has been continuously highlighted. With the increasingly close exchanges with countries along the "Belt and Road" and the frequent development of economic and cultural activities, the demand and requirements for foreign language talents have become more stringent in recent years. Japan is one of China's cooperation countries along the "21st Century Maritime Silk Road" strategy, and is also an important country for Dalian to conduct foreign economic and trade cooperation. The China-Japan Trade and Investment Cooperation Report (2019) were released in Dalian on September 27, 2019. The "Report" released the index of cooperation between China's provinces, autonomous regions and municipalities and Japan. The index rankings show that Shanghai, Jiangsu, Guangdong, and Beijing ranked firmly in the top four, and Shandong Province jumped to fifth place; the three provinces in Northeast China performed better in Liaoning. Among the 5 cities listed separately, Dalian has outstanding trade cooperation with Japan, ranking first among the cities listed separately.

Japan is Dalian's largest foreign trade market. In the past two years, the goods trade between Dalian and Japan has enjoyed a good momentum, and the total trade volume has maintained a growth rate of more than $10 \%$. In 2018, the total goods trade between Dalian and Japan reached 13.24 billion US dollars, the highest peak in the past five years, accounting for $18.3 \%$ of Dalian's 
total foreign trade. Dalian's exports to Japan were US \$ 7.72 billion, an increase of about $10 \%$ over 2017; imports from Japan were US \$ 5.52 billion, an increase of $15.5 \%$ over 2017 .

Judging from the bilateral investment between Dalian and Japan, as of April 2019, Japan has invested more than 4,800 companies in Dalian, with a cumulative actual investment of about 18.62 billion US dollars. The Japanese market is of great significance to Dalian. There are more than 2,000 existing companies in Dalian software and service outsourcing industry with an annual operating income of more than 100 billion yuan. The starting point of its development is from the Japanese market. The outsourcing of Dalian business to Japan accounts for more than $60 \%$ of the city's offshore outsourcing business. At the same time, Dalian enterprises have also "going out" to open up the Japanese market. In 2018, 3 companies in Dalian invested in Japan to set up wholly-owned enterprises. Because Japanese companies do not use localized management like European and American companies, Japanese companies mostly use the Japanese accounting system to settle accounts. In the outsourcing business in Japan, the number of companies engaged in Japanese financial outsourcing has also gradually increased; the IT industry produces corresponding software for Japanese financial companies. You also need to have some knowledge of Japanese bookkeeping. Therefore, the demand for bookkeeping talents is also increasing.

This course has been researched and established for this need. It is a brand-new field, which is different from other humanistic quality elective courses, and its application is stronger. Students can master a skill after studying.

Here are the innovations of this course:

The establishment of this course has undergone early business research (such as Accenture, Nomura Information, etc.), and Japanese bookkeeping talents are indeed urgently needed by enterprises.

The content of this course is innovative and it is an emerging cross-course. It makes up for the gap in the "Japanese bookkeeping" course on the campus. It is a powerful supplement to the professional knowledge of Japanese and accounting students, and a strong support for the improvement of students' knowledge and skills in other majors. Japanese students who have studied this course can take the Japanese Bookkeeping Level III exam to expand their employment horizons.

This course is promising. Because foreign languages are more instrumental, with the popularization of foreign language teaching, pure foreign language students have obviously lost their advantages in employment, so major high corrections are reforming foreign language majors. Tohoku Normal University has taken the lead in joining the "Japanese for Welfare" program in Japanese. Some schools use the five-year program to teach "Japanese +". This course has been set up as a compulsory professional course in some universities in Dalian. With the development of this trend, our Japanese major will continue to join other auxiliary subjects in the future, such as: Japanese bookkeeping.

\section{APPLICATION OF EFFECTIVE TEACHING IN JAPANESE}

\section{A. Open effective teaching mode-O-AMAS teaching model}

O-AMAS teaching model is a result-oriented and effective teaching model independently developed by Nankai University's Nankai Effective Teaching (NKET) based on the reality of Nankai, inheriting the culture of Nankai, and solving the problems of Nankai in 2017. The O-AMAS effective teaching model adopts OBE teaching design ideas. The model includes teaching objective design (Objective, O), rapid activation (Activation, A), multi-learning (M), effective assessment (Assessment, A), briefly summarize (Summary, S) five links. The model is guided by students 'outcome and driven by the positive interaction between teachers and students. Through more than a hundred independently developed effective interactive activities, the model guides students' active learning and deep learning, from teaching methods, teaching techniques, teaching organization, and Management, and other aspects, to achieve deep penetration of teaching goals, deep participation of teaching objects, teaching methods to follow, teaching effects visible and controllable, to enhance the learning experience of students, to build students "laughing on the face, light on the eyes, the process is interesting "Learning Effectively" in the "Four have" Class. ${ }^{1}$

- Clear teaching goals (O): Make specific, achievable, measurable, realistic, time-bound teaching goals.

In the past, the vocabulary of "understanding" and "understanding" were used a lot, but how to detect "understanding" and "understanding"? Vocabularies like this that are not measurable by the rating scale should be avoided or used as little as possible in the formulation of future teaching goals.

- Rapid activation (A): Use examples to quickly activate learners' bodies, emotions, and cognition. Not only the activation of knowledge, but also the psychological resonance of students.

\footnotetext{
https://baike.baidu.com/item/O-AMAS
} mode/23751133 teaching 
- Diversified learning (M): a multi-learning model that combines student-centered teaching methods.

Learning community-oriented teaching mode, teachers are supporters, helpers, collaborators, and companions in the learning process of students. By designing the teaching process, teachers stimulate students' learning interest and form learning motivations. Teachers should be good at creating teaching situations, prompting clues between new and old knowledge, helping to construct learning meanings, and organizing collaborative learning to make learning more effective. Emphasize that teachers and students are in a learning community, and their representative forms are cooperative learning and project-based learning.

- Effective assessment (A): The assessment scores are assessment and promotion assessment.

The evaluation of academic evaluation can be understood as a summative evaluation, which is an evaluation of the educational quality of a semester or a subject. The purpose is to make a conclusive evaluation of the quality of students' periodic learning. Grading is an important way to test the development of students' comprehensive use of language ability, and it is also one of the important indicators reflecting the teaching effect and the quality of school running. Such as final exam, final exam, etc. Promoting learning assessment is based on "promoting", and promoting learning through assessment is its ultimate purpose. Therefore, unlike academic assessment, facilitation assessment is a formative assessment. Formative assessment is often carried out in the form of informal tests or unit tests. Through formative evaluation, teachers can keep track of students' progress in learning, obtain continuous feedback during the teaching process, and provide a reference for teachers to adjust teaching plans and improve teaching methods at any time. Effective assessment in the classroom, promoting the promotion of learning assessment, changing the traditional thinking of "grading assignments", students did not gain from the scores; scores + comments, comments were offset by the scores, still no gain; only reviews, effective feedback, that is, students How well you do + how students do it will be better, which can effectively improve students' enthusiasm for learning. For example, for a voice homework review, you can write "The sound is loud, clear, good tones, and accurate pronunciation, but the long sound is not obvious. Pay attention to the long sound re-recording, the effect will be better!" Like this, an effective evaluation feedback model is these:

- Places to be affirmed $\rightarrow$ Directions for improvement or hard work $\rightarrow$ Real praise and encouragement.
- Brief Summary (S): Deepening of student participation in reflection, a brief summary in time. It is necessary to consolidate knowledge and deepen reflection through this link.

\section{B. Application and practice of $O-A M A S$ teaching model in Japanese bookkeeping course}

The Japanese bookkeeping course is an elective course on the school. It is aimed at students of various majors in the school, especially students majoring in Japanese and accounting. The course starts with the basics and goes from shallow to deep. The purpose of this course is to enable students to master basic Japanese accounting knowledge in addition to a wealth of relevant professional knowledge. After completing the study, they will reach the third level of bookkeeping. And can deal with the daily Japanese financial work of ordinary business. At the same time, through learning to improve students 'understanding of Japan, enrich the knowledge structure and improve their comprehensive ability, so as to broaden the employment channels for students at graduation and improve the quality of students' employment. The course has a total of 24 hours. In the spring semester of 2017 , the course started for the first time. The number of electives for the first course was 53. So far, it has successfully started 4 courses with a total of 224 people. And some Japanese students successfully passed the Japanese bookkeeping level three exam. Since the beginning of the course, the content of the lesson is relatively new, and the students' grasp of the situation is uncertain. Therefore, the course has always used face-to-face instruction, and has not introduced the method of online teaching. Master the ability of understanding, this course realizes online and offline mixed teaching, and online student interaction is added in the course of teaching with good response. According to the O-AMAS teaching model, we have made the following reforms in curriculum organization:

\section{- Clear teaching goals}

The teaching objective of this course is mainly to allow students to take the level 3 of bookkeeping through learning and to be able to deal with primary financial problems. The main knowledge points of the third-level exam are: selecting the correct subjects for entry according to transaction information, financial calculation problems, records of various ledgers, production of balance sheets and income statements, etc. In the course of teaching, we refine the teaching goals of each lesson, and carry out a variety of teaching methods around the teaching goals. For example, the content of the first lesson is "bookkeeping basics". Non-accounting students do not know what accounting work does. Therefore, in the first lesson, we set the goal of the lesson so that students can integrate with them through learning. Illustrate the "bookkeeping" work in 
real life, and explain the "bookkeeping" knowledge contained in this example. By setting goals in this way, students can combine their daily life with their studies, which can stimulate their interest in learning and encourage students to connect what they have learned with their actual lives.

\section{- Quick activation}

"Bookkeeping" knowledge is closely related to us. To quickly arouse students' interest in learning, it is necessary to let students know that this knowledge is inseparable from daily learning and future work. In a modern society where information is highly developed, online shopping has become popular. In order to motivate students in the classroom, according to the teaching goals of each class, we will give examples of life and let students continue to think about "bookkeeping" in the context of the examples.

\section{- Diversified learning}

In the multi-learning stage, because of the particularity of this course as an elective course, we mainly use cooperative learning. The theoretical basis of cooperative learning is the cooperative goal structure theory of Doiqi (M. Deutsch, 1949). The cooperative goal structure makes the communication between group members more frequent. They help each other and encourage each other. Doiqi's collaborative goal structure sets up a situation where team members can reach their own goals only when the team is successful. Therefore, in order to achieve their own goals, team members must help each other to achieve the team's success. In other words, this way of rewarding on the basis of group results creates positive interpersonal relationships, which enables group members to give positive social reinforcement to the efforts made by their peers, such as praise and encouragement. This is not found in the traditional classroom structure of competitive goals. ${ }^{2}$ As this course is an elective course on campus, students' grades and majors are not easy to control, so how to complete the group study of cooperative learning is the first and difficult problem we encountered in teaching reform. Students of different majors and different grades may not know each other, let alone be familiar, which makes it more difficult to group. Cooperative learning reflects the spirit of teamwork and is a direct expression of the course's ideology. Students learn both knowledge and teamwork in the classroom. Therefore, considering the differences between grades, we first classify the students according to the grade. After counting the number, the principle of voluntary registration by the group leader is adopted. Decide. The completion score of the group work is determined by the division of the labor, and the final grade is composed of the group grade and the individual grade. After the grouping is

2 https://baike.so.com/doc/6234946-6448301.html completed, the teacher will lead the group to complete the "ice-breaking" activity in the classroom, and at the same time establish a WeChat group for each group. Cooperative learning is also a way to motivate students to learn. Students who can recommend themselves as team leaders often have sufficient self-confidence in themselves. Through group activities, they also exercise their leadership and organizational skills.

- Effective evaluation

In accordance with the O-AMAS model, we have adopted facilitation evaluation in teaching reform. In the new round of teaching, our specific exercises have been changed to online. However, for group work after class, we still chose the offline method. Of course, students can discuss online, but the homework must be submitted in paper version. For example: in the first class of study, I will assign a large assignment to students. Simulate a supermarket and use the knowledge points learned in each lesson to make transaction entries and transfers. During the lesson, you learned other bookkeeping methods and added them to the supermarket's bookkeeping after returning. The financial statements at the end of the year have been completed with previous data. This homework will be taught for the entire lesson. The final homework submitted by the group is a thick stack of paper. Then with the completion of this process, students really apply what they have learned. Of course, after completing each week, homework must be handed in so that the teacher can find errors in the homework, and timely correction will not affect the final financial statement. Our evaluation strictly follows the law of promoting learning evaluation, that is, areas worthy of recognition $\rightarrow$ directions for improvement or efforts $\rightarrow$ sincere praise and encouragement.

\section{- $\quad$ Brief summary}

Before the end of each class, a "mind map" method is used to help students sort out knowledge points, complete reflection and deepen.

\section{CONCLUSION}

This teaching reform first adopted the O-AMAS effective teaching model to make the class more interesting, the students 'participation is higher, and the students' enthusiasm for learning was mobilized. Secondly, in the course of teaching, humanistic care and teamwork were increased, so that self-centered students realized the importance of teamwork. At the same time, students who have confidence in themselves, exercise and develop themselves in the process of serving as team leader. And in this reform, online exercises are added, and the goal of mixed online 
and offline teaching is basically completed, laying a foundation for the next step in achieving online teaching.

\section{References}

[1] Xiangzhuo, Exploring Effective Teaching Methods of Japanese Writing Course in Colleges and Universities, Journal of Shandong Agricultural Engineering College, 2016 (4), 89-90

[2] Jiang Yang, Selection of Effective Teaching Strategies for College Japanese, China Off-School Education, China OffSchool Education, 2014 (3), 89

[3] Xiaoxia Li, Research on Multimodal Teaching of Advanced Japanese from the Perspective of Effective Teaching, Journal of Communication Teachers College, 2014 (12), 100-102

[4] Xiao Xiao, On Effective Teaching Models of Japanese International Trade Practice Training in Private Colleges and Universities, Academic Theory, 2013 (4), 263-265

[5] Li Haojun and others. Teaching practice innovation of first-class professional courses from the perspective of effective teaching, Journal of Zhejiang University of Technology, 2020(3), 342347

[6] Xiao Xiyan and others, Research on Effective Teaching Behaviors in College English Blended Teaching, Chinese Journal of Multimedia and Network Teaching, 2020(10), 100102. 